\title{
Deferiprone Treatment in Aged Transgenic Tau Mice Improves Y-Maze Performance and Alters Tau Pathology
}

\author{
Shalini S. Rao ${ }^{1}$. Larissa Lago ${ }^{1}$ - Irene Volitakis ${ }^{1}$. Jay J. Shukla ${ }^{1} \cdot$ Gawain McColl $^{1}$ - David I. Finkelstein ${ }^{1}$. \\ Paul A. Adlard ${ }^{1}$ (D)
}

Accepted: 12 November 2020

(C) The American Society for Experimental NeuroTherapeutics, Inc. 2021, corrected publication 2021

\begin{abstract}
The accumulation of neurofibrillary tangles (NFTs), which is composed of abnormally hyperphosphorylated tau aggregates, is the classic neuropathology associated with cognitive dysfunction in tauopathies such as Alzheimer's disease (AD). However, there is an emerging theory suggesting that dysregulation in cerebral iron may contribute to NFT formation. Iron is speculated to bind to tau and induce conformational changes of the protein, potentially leading to subsequent aggregation and cognitive decline. Deferiprone (DFP) is a clinically available iron chelator, which has demonstrated potential therapeutic advantages of chelating iron in neurodegenerative disorders, and is currently in clinical trials for AD. However, its effect on tau pathology remains unclear. Here, we report the effects of short-term DFP treatment (4 weeks, $100 \mathrm{mg} / \mathrm{kg} / \mathrm{daily}$, via oral gavage) in a mixedgender cohort of the $\operatorname{rTg}_{(\operatorname{tauP} 301 \mathrm{~L})} 4510$ mouse model of tauopathy. Our results revealed that DFP improved Y-maze and open field performance, accompanied by a $28 \%$ decrease in brain iron levels, measured by inductively coupled plasma mass spectrometry (ICP-MS) and reduced AT8-labeled p-tau within the hippocampus in transgenic tau mice. This data supports the notion that iron may play a neurotoxic role in tauopathies and may be a potential therapeutic target for this class of disorders that can be modulated by the clinically available metal chelator DFP.
\end{abstract}

Key Words Tau $\cdot$ iron $\cdot$ deferiprone $\cdot$ tauopathies $\cdot$ therapeutic

\section{Introduction}

Neurofibrillary tangles (NFTs) are the primary neuropathological feature of a class of disorders referred to as tauopathies, which includes Alzheimer's disease (AD), progressive supranuclear palsy (PSP), and frontotemporal dementia (FTD) [1]. The primary component of NFTs is aggregates of the abnormally hyperphosphorylated tau protein [2]. The accumulation of NFTs is strongly associated with the onset and progression of neurodegeneration [3]; however, there is considerable diagnostic overlap between impaired and unimpaired aged individuals [4], suggesting that other pathways or pathologies may be involved in tauopathies. While there are a number of potential therapeutic candidates [5], iron is gaining traction

Paul A. Adlard

paul.adlard@ florey.edu.au

1 Melbourne Dementia Research Centre, The Florey Institute of Neuroscience and Mental Health, The University of Melbourne, Parkville, Victoria 3052, Australia as an independent predictor of disease progression [6] , as well as a factor involved in the regulation of tau [7-9].

Age-related changes in brain iron levels are proposed to be a potential biomarker for the development of $\mathrm{AD}$ and $\mathrm{PD}[6$, $10,11]$, as its accumulation can impact brain health and function through several factors such as promoting inflammation and disrupting metabolic function and neurotransmission [12]. The consequences of abnormal elevations of iron in the brain are well evidenced in a rare class of disorders referred to as neurodegeneration with brain iron accumulation (NBIA), which results in parkinsonism, cognitive decline, neuropsychiatric abnormalities, and, to an extent, tau pathology [13]. In animal models, dysregulation of iron causes impaired motor and cognitive function and induces tau pathology [14-20]. Recent human studies have reported simultaneous increases in iron and tau pathology, which is associated with an acceleration in the rate of cognitive decline in neurodegeneration $[6$, $10,21]$. Furthermore, neurotoxic levels of iron are found to be concentrated with tau in NFTs [22-24] and several studies have suggested a putative interaction between iron and tau in neurodegeneration [25-27]. Iron is reported to mediate 
tangle formation through several mechanisms such as inducing tau hyperphosphorylation via the upregulation of tau kinases and by directly binding to tau, which may potentially result in a conformational change in the protein to promote aggregation into NFTs [7, 22, 28]. As such, the use of iron chelators is currently being explored as a therapeutic avenue for the treatment of tauopathies.

Deferiprone (DFP) is a membrane-permeant bidentate chelator [29] commonly used for the treatment of iron overload disorders such as hemosiderosis [30] and Friedreich's ataxia [31]. In PD clinical trials (FAIR PARK II; ClinicalTrials.gov identifier: NCT02655315) [32], DFP improved clinical symptoms and reduced brain iron levels measured by MRI and is currently underway in clinical trials for $\mathrm{AD}$ (Deferiprone to Delay Dementia, The 3D Study, ClinicalTrials.gov Identifier: NCT03234686). Furthermore, DFP has been shown to reduce tau hyperphosphorylation and downregulate the tau kinase glycogen synthase kinase 3-beta (GSK3 $\beta$ ) in animal models, which is suggested to be one of the main culprits in the development of tauopathies [33, 34]. However, the effects of DFP on tau pathology are still unclear. Based on the accumulating literature suggesting an interaction between iron and tau in neurodegeneration, we hypothesized that targeting iron with DFP would reduce tau pathology and improve cognitive function. To investigate this, the therapeutic efficacy of DFP was evaluated in the symptomatic stages of neurodegeneration in 12-month-old rTg4510 mice overexpressing the human tau mutation P301L (referred to as rTg4510) [35] for 4 weeks. We acknowledge that long-term DFP treatment is important in the pharmacotherapy for $\mathrm{AD}$; however, this study was designed to understand the shortterm effects of DFP to examine how effectively the compound elicited pharmacological benefits and to lay a foundation to further explore the effects of DFP in tau-mediated neurodegeneration. Our results revealed that DFP improved short-term spatial reference memory as measured by Y-maze and reduced hyperactivity and anxiety-like behavior in the open field test. This was accompanied by reduced AT8-labeled p-tau in the hippocampus and a downregulation of the tau kinases GSK $3 \beta$ and cyclin-dependent kinase 5 (CDK-5). In addition, DFP reduced brain iron levels as measured by inductively coupled plasma mass spectrometry (ICP-MS). These results demonstrate the potential clinical benefits of DFP in the symptomatic stages of neurodegeneration in tauopathies.

\section{Materials and Methods}

\section{Ethical Approval}

All animal experimental procedures were approved by the Florey Institute of Neuroscience Animal Ethics Committee (16-105) and conducted in accordance with the Prevention of Cruelty to Animals Act and the NH\&MRC Code of Practice for the Use of Animals for Scientific Purposes.

\section{Animals}

This study used the $\mathrm{rTg}_{(\operatorname{tauP} 301 \mathrm{~L})} 4510$ mouse model of tauopathy (referred as rTg4510) that overexpresses the human tau mutation P301L which is associated with heredity tauopathies $[35,36]$. The original breeding animals for this colony were a kind gift from the Mayo Foundation for Medical Education and Research. Drug treatments were performed in a mixed-gender cohort and commenced at 12 months of age. Our previous studies demonstrated that rTg4510 mice have profound behavioral deficits at this age, in addition with a significant accumulation of brain iron [37] and tau pathology, therefore allowing us to examine the use of DFP as a treatment strategy. Mice were housed in Techniplast IVC cages with free access to mouse chow and water. Food and water were checked daily during the week by staff members of the Core Animal Services, Florey Institute of Neuroscience and Mental Health. The cages were lined with a bed of sawdust, and mice were given a solid enclosure as enrichment and tissue paper for nesting. From day 1 of treatment experiments, animals were weighed daily (including weekends) to determine drug dose and to monitor any adverse reactions to treatment, and summary weight data is included in the supplementary information (Fig. S2a). The total DFP treatment was performed over a total of 31 days. Behavioral experiments were performed on the following days: locomotor (open field test) on day 17, rotarod on days 18-19, Y-maze on day 21, and Morris water maze (MWM) on days 23-30.

\section{Drug Preparation and Treatment}

DFP (3-hydroxy-1,2-dimethyl-4(1H)-pyridone; SigmaAldrich, MO, USA) was dissolved by probe sonication in standard suspension vehicle (SSV; $\mathrm{NaCl} 0.9 \% \mathrm{w} / \mathrm{v}$, carboxy methyl cellulose $0.05 \% \mathrm{w} / \mathrm{v}$, benzyl alcohol $0.05 \% \mathrm{v} / \mathrm{v}$, Tween $80,0.04 \% \mathrm{v} / \mathrm{v})$. Sonication was carried out at room temperature in 2-3 rounds of $15 \mathrm{~s}$. Sonication was set at an amplitude of $40 \%$, until DFP was completely dissolved. Mice were treated for 4 weeks with $100 \mathrm{mg} / \mathrm{kg} /$ daily of DFP (total: $n=9$; males: $n=5$ and females: $n=4$ ), by oral gavage using a 23-gauge gavage needle. Vehicle-treated mice ( $\operatorname{Tg} 4510: n=$ 9; males: $n=4$, females: $n=5$; wild-type (WT): $n=9$; males: $n=5$, females: $n=4$ ) were gavaged with an equivalent volume of SSV relative to body weight.

\section{Morris Water Maze}

The MWM was performed as previous described [37]. Briefly, the experiment was performed in a 1.4-m-diameter circular pool filled with water, made opaque with nontoxic 
paint maintained at $23-25^{\circ} \mathrm{C}$ at $22.5-35 \mathrm{~lx}$ lighting. Mice were acclimated by allowing them to explore the water maze for $60 \mathrm{~s}$ on the day before training commenced, followed by six consecutive days of task acquisition training (spatial learning) of four 90-s trials per day. After $24 \mathrm{~h}$, the probe trial was performed to assess retention task. Data was collected using EthoVision automated tracking system (Noldus, Wageningen, Netherlands).

\section{Y-Maze}

The Y-maze was performed as previously described [38] and performed at a $\sim 22.5-35 \mathrm{~lx}$ lighting level. Briefly, the three identical arms of the Y-maze were randomly designated using Excel as start, novel, and other arm for each mouse, with different visual cues at the end of each arm. The Y-maze arena was covered in $2 \mathrm{~cm}$ of sawdust, and each mouse was randomly assigned a start and novel arm using excel. Mice were subject to 2-trial Y-maze test separated by a 1-h interval to assess spatial recognition memory. The first trial (training) allowed the mouse to explore 2 arms (start and other) freely for $10 \mathrm{~min}$. The retention trial commenced $1 \mathrm{~h}$ after training, and the mouse could freely explore all three arms of the maze for $5 \mathrm{~min}$. Data was collected using the EthoVision automated tracking system using a ceiling-mounted CCD camera.

\section{Rotarod}

Rotarod was performed as previously described [37] to assess motor coordination. Lighting was set between 45 and $50 \mathrm{~lx}$. Briefly, the rotarod was performed over 2 days and consisted of $3 \times 5$-min inter-trials separated by $1 \mathrm{~h}$ with a starting speed of 4 revolutions per min (rpm), increasing by 1 rpm every $8 \mathrm{~s}$ over the $5 \mathrm{~min}$. On day 1 , mice were placed on the rotarod (lane width, $50 \mathrm{~mm}$; rod diameter, $30 \mathrm{~mm}$ ) for $2 \mathrm{~min}$ at a set speed of $4 \mathrm{rpm}$ to acclimate to the equipment and the task. Training commenced $1 \mathrm{~h}$ after acclimation. On day 2 , the time spent on the rotarod (fall latency) for each mouse was recorded and averaged over the 3 inter-trials.

\section{Locomotor (Open Field Test)}

Mice were placed in clear perspex tracking chambers, "equipped with a grid of infrared beams (Coulburn TruScan, USA) for $60 \mathrm{~min}$. The tracking software recorded the total movements within the $60 \mathrm{~min}$ in the floor plane by the interruption of a grid of beams.

\section{Tissue Collection}

Animals received a final dose of DFP an hour before tissue collection. Mice were euthanized (with sodium pentobarbital, $80 \mathrm{mg} / \mathrm{kg}$, via intraperitoneal injection) followed by transcardial perfusion $(0.1 \mathrm{M}$ phosphatebuffered saline (PBS)). From the left hemisphere, the cerebellum, hippocampus, and cortex were rapidly dissected and each brain sample along with the remaining tissue from the left hemisphere (referred to as whole tissue) was stored at $-80{ }^{\circ} \mathrm{C}$ until analysis. The right hemisphere was drop fixed in $4 \%$ paraformaldehyde (PFA) overnight and subsequently cryopreserved in $30 \%$ sucrose in PBS. Sucrose was changed every 4 days, and after 2 weeks, the brains were snap-frozen. Selected brains were subsequently cryosectioned (30 $\mu \mathrm{M}, 1: 10)$ and mounted on microscope slides (Grale Scientific, Melbourne, Australia) for histological analysis.

\section{Metal Analysis}

Metal quantification was performed in whole tissue: samples were weighed and homogenized by probe sonication (2-3 rounds of sonication for $15 \mathrm{~s}$ on ice, $40 \%$ amplitude) in $1 \mathrm{~mL}$ of homogenization buffer (Dulbecco's PBS with EDTA-free protease inhibitor and Roche PhosSTOP, SigmaAldrich). For ICP-MS, brain metal content was measured in homogenized samples. For size exclusion chromatography (SEC)-ICP-MS analysis, 100-200 $\mu \mathrm{L}$ of total homogenate was centrifuged at $100,000 \times \mathrm{g}$ for $30 \mathrm{~min}$ at $4{ }^{\circ} \mathrm{C}$. The supernatant was collected, and both the pellet and supernatant were stored at $-80{ }^{\circ} \mathrm{C}$ until further use.

\section{ICP-MS}

ICP-MS was performed as previously described [39]. Briefly, brain homogenates $(50 \mu \mathrm{L})$ were lyophilized and digested with nitric acid $\left(\mathrm{HNO}_{3}, 65 \%\right.$ Suprapur; Merck Millipore, Billerica, MA, USA), which will dissociate iron from DFP [40], overnight at room temperature. The samples were further digested by heating at $90{ }^{\circ} \mathrm{C}$ for 20 min using a heating block. Samples were then removed from the heating block, and an equivalent volume of hydrogen peroxide $\left(\mathrm{H}_{2} \mathrm{O}_{2}\right)(30 \%$ Aristar; BDH. Radnor, PA, USA) was added to each sample. Samples were allowed to stop effervescing (digesting) for $\sim 30 \mathrm{~min}$, before heating again for a further $15 \mathrm{~min}$ at $70^{\circ} \mathrm{C}$. The average reduced volume was determined, and the samples were further diluted with $1 \% \mathrm{HNO}_{3}$ diluent. The instrument was calibrated using $0,5,10,50,100$, and $500 \mathrm{ppb}$ of certified multi-element ICP-MS standard calibration solutions (ICPMS-CAL2-1, ICP-MS-CAL-3, and ICP-MS-CAL-4; AccuStandard New Haven, CT, USA) for a range of elements. A certified internal standard solution containing $200 \mathrm{ppb}$ of yttrium (Y89) was used as an internal control (ICP-MS-ISMIX1-1, AccuStandard). Plasma samples were diluted with $1 \% \mathrm{HNO}_{3}$ prior to ICP-MS but were not lyophilized or digested overnight like the brain homogenates. 


\section{Size Exclusion Chromatography-ICP-MS}

SEC-ICP-MS analysis was performed using the previously described method for injection of $100 \mu \mathrm{g}$ of protein [41]. Samples were chromatographically separated using a $3-\mathrm{mM}$ 150A BioSEC- 3 column $(4.6 \times 300 \mathrm{~mm})$ with $200 \mathrm{mM}$ ammonium nitrate containing internal standard $\left({ }^{133} \mathrm{Cs},{ }^{121} \mathrm{Sb}\right.$; $10 \mu \mathrm{g} / \mathrm{L}$ each), $\mathrm{pH} 7.5$, at a flow rate of $0.4 \mathrm{~mL} / \mathrm{min}$. The HPLC was directly connected to a Micro Mist nebulizer (Glass Expansion, Melbourne, Australia) fitted to a 203 7700x ICP-MS (Agilent Technologies, Santa Clara, CA). Helium was used as the collision gas ( $3 \mathrm{~mL} / \mathrm{min})$ to minimize polyatomic interferences with all elements. The following elements were analyzed: ${ }^{56} \mathrm{Fe},{ }^{63} \mathrm{Cu},{ }^{66} \mathrm{Zn},{ }^{121} \mathrm{Sb}$, and ${ }^{133} \mathrm{Cs}$.

\section{Histology}

Slides were incubated in citrate buffer ( $\mathrm{pH}$ 6.0; Sigma-Aldrich, $\mathrm{MO}$ ) and microwaved on high for $2 \mathrm{~min}$ and left to cool for $2 \mathrm{~h}$. Slides were blocked in $10 \%$ normal goat serum (with $0.03 \%$ Triton X-100 in $0.1 \mathrm{M}$ phosphate buffer (PB) for $30 \mathrm{~min}$ at room temperature (RT)) then incubated with primary antibody (NeuN, 1:1500 (Merck Millipore, Billerica, MA, USA), or AT8, 1:1000; in $0.1 \mathrm{M}$ PBS, $0.01 \%$ normal goat serum, and $0.03 \%$ Triton $\mathrm{X}-100$ ) for $48 \mathrm{~h}$ at $4{ }^{\circ} \mathrm{C}$ in a humidified chamber. Slides were washed with $0.1 \mathrm{M}$ PBS $(3 \times 10 \mathrm{~min})$ and incubated for $3 \mathrm{~h}$ at RT with either goat anti-mouse or goat anti-rabbit IgG poly-horseradish peroxidase (HRP; Millipore) diluted in $0.1 \mathrm{M}$ PB, followed by a further wash. Slides were then incubated with avidin peroxidase (diluted in $0.1 \mathrm{M}$ PBS with $0.075 \%$ Triton $\mathrm{X}-100$ ) for $1 \mathrm{~h}$ at $\mathrm{RT}$ and then rinsed. The slides were incubated in a nickel-3,3-diaminobenzidine (DAB) solution containing $0.01 \% \mathrm{DAB}, 0.025 \%$ cobalt chloride, and $0.02 \%$ ammonium nickel sulfate in $0.1 \mathrm{M}$ PBS at RT and were further developed by adding $0.001 \%$ hydrogen peroxide for 5 min. Sections were then washed, dehydrated, and coverslipped using DPX mounting medium. Stereological estimates of tau inclusions (AT8-labeled tau) were quantitated using Stereo Investigator (version 11.06.02, MBF Bioscience, Williston, VT USA), including the entire hippocampus (which includes the dentate gyrus and cornu ammonis (CA) subfields: CA1, CA2, and CA3) as well as the frontal cortex (that includes regions of the medial and lateral parietal association cortices, primary somatosensory cortex, along with some regions of the primary and secondary visual cortices).

\section{Western Blot}

Hippocampus and frontal cortical samples were weighed and homogenized in homogenization buffer at a ratio of 1:10 (w/v) by probe sonication (as described above). For immunoblotting, total homogenate was centrifuged at $100,000 \times \mathrm{g}$ for $30 \mathrm{~min}$ at $4{ }^{\circ} \mathrm{C}$. The supernatant was collected, and the pellet was resuspended in homogenization buffer. Protein concentration was determined by BCA protein assay. Samples were prepared for SDS-PAGE by the addition of $4 \times$ NuPage LDS sample buffer (Life Technologies, Melbourne, Australia) and 10× NuPage reducing agent (Life Technologies; both to a final $1 \times$ concentration) to $5 \mu \mathrm{g}$ of protein. Samples were heated to $90^{\circ} \mathrm{C}$ for $5 \mathrm{~min}$ and separated in $4-12 \%$ Bis-Tris gel (Life Technologies) alongside the Odyssey One-Color protein molecular weight marker (Millennium Science, Melbourne, Australia). Gels were run at $140 \mathrm{~V}$ for $80 \mathrm{~min}$ in $1 \times$ MES buffer (Life Technologies) and then transferred to iBlot PVDF membranes by iBlot (Life Technologies). Membranes were blocked for $30 \mathrm{~min}$ in $1 \times$ Tris-buffered saline with Tween 20 (TBST; $10 \mathrm{mM}$ Tris, $150 \mathrm{mM} \mathrm{NaCl}, 0.1 \%$ Tween 20) containing 5\% skim milk powder and $1 \%$ BSA at RT then incubated with primary antibody (Table 1) diluted in 3\% BSA in TBST overnight at $4{ }^{\circ} \mathrm{C}$ or $1 \mathrm{~h}$ at RT. Blots were rinsed in TBST $(3 \times 5 \mathrm{~min}$ washes) and incubated with IRDye secondary antibody (Millennium Science) diluted in $0.01 \%$ SDS in TBST for $30 \mathrm{~min}$ at RT. Blots were washed again in TBST, followed by 3 quick washes in PBS and imaged using a LI-COR Odyssey Imaging system (LI-COR Biosciences, Lincoln, $\mathrm{NE}$ ). Blots were analyzed using Image Studio Lite software, and samples were normalized to $\beta$-actin as a loading control. Normalized $\beta$-actin values were used to calculate the ratio of phosphorylated protein/total protein ratios.

\section{Statistical Analysis}

Statistical analysis was performed using GraphPad Prism 8 (2019). Results are expressed as mean \pm standard error of the mean (SEM). Behavior tests and immunoblots comparing between genotypes and treatment groups were analyzed using one-way ANOVA, with Tukey's post hoc test. Unless noted, all other comparisons are made using unpaired two-tailed $t$ tests. Statistical significance was accepted at $p<0.05$ and is denoted with a single asterisk (*). Additional statistical distinctions are made at $p<0.01(* *)$ and $p<0.001(* * *)$.

\section{Results}

\section{No Improvement in Morris Water Maze Performance Following DFP Treatment}

Spatial acquisition (learning curve) was assessed by latency to escape during the 6-day training phase of the task (Fig. 1a). Comparison of the learning curves between WT mice and rTg4510 showed significantly higher values in escape latency in $\mathrm{rTg} 4510$ mice $(p<0.001)$, indicating that $\mathrm{rTg} 4510$ mice failed to learn the task over the training period and was not improved with DFP $(p<0.0001$ compared to WT). This was also verified in the recall task (probe trial; Fig. 1b), in which 
Table 1 List of antibodies

\begin{tabular}{llll}
\hline Antibody & Dilution & Company & Catalog\# \\
\hline Total tau & $1: 1000$ & DAKO & A0024 \\
p-tauSer396 & $1: 1000$ & Invitrogen & $35-5300$ \\
p-tauSer202/205 & $1: 1000$ & Invitrogen & MN1020 \\
AT100 & $1: 1000$ & Invitrogen & MN1060 \\
p-tauThr231 & $1: 1000$ & Invitrogen & $35-5200$ \\
GSK3ß & $1: 1000$ & Cell Signaling & $9315 \mathrm{~S}$ \\
p-GSK3ß Ser9 & $1: 1000$ & Cell Signaling & 9336 \\
CDK5 & $1: 200$ & Santa Cruz Biotechnology & sc-6247 \\
p-CDK5 Thr15 & $1: 200$ & Santa Cruz Biotechnology & sc-377558 \\
Ferroportin/SLC40A1 & $1: 500$ & Novus Biologicals & NBP1-21502 \\
Ferritin & $1: 1000$ & Abcam & Ab75973 \\
PP2A subunit A & $1: 1000$ & Cell Signaling & $2041 \mathrm{~S}$ \\
PP2A subunit B & $1: 1000$ & Cell Signaling & $2290 \mathrm{~S}$ \\
PP2A subunit C & $1: 1000$ & Cell Signaling & 2259 \\
Pin-1 & $1: 1000$ & Cell Signaling & $3722 S$ \\
PME-1 & $1: 1000$ & Thermo Fisher Scientific & PIEPA5-27754 \\
\hline
\end{tabular}

WT mice spent an average of $31.2 \mathrm{~s}$ in the target quadrant, while vehicle-treated (rTg4510) mice and DFP-treated mice spent $19.75 \mathrm{~s}(p<0.05$ compared to WT) and $21.22 \mathrm{~s}(p<0.05$ compared to WT), respectively, in the target quadrant.

\section{DFP Improved Y-Maze Performance}

On average, WT mice spent $42.8 \%$ of the total duration ( $5 \mathrm{~min}$ ) in the novel arm, which was significantly higher compared to that of vehicle-treated rTg4510 mice (28.3\%, Fig. 1c, $p<0.0001)$. This demonstrates poor working memory and exploratory behavior in rTg4510 mice. Short-term treatment with DFP in rTg4510 mice improved Y-maze performance, as indicated by an increase in the percentage duration spent in the novel arm $(37.3 \% ; p<0.05$, compared to vehicle-treated rTg4510 mice). We further explored the effects of DFP in Y-maze performance by examining the total number of novel arm entries (bouts) and found no difference between genotypes or treatment groups (Sup. Fig. 2f).
Fig. 1 Effects of DFP on cognition and motor function. Spatial reference memory was measured by MWM. (a) Spatial learning (two-way repeated measures ANOVA with Tukey's post hoc, $p>0.1$ ). (b) Recall task. (c) Short-term reference memory was measured by Y-maze. (d) Motor coordination as assessed by rotarod. One-way ANOVA, Tukey's post hoc test. Error bars represent \pm SEM. $\mathrm{WT}_{\mathrm{SSV}}=$ vehicle-treated WT mice; $\mathrm{Tg}_{\mathrm{SSV}}$ = vehicle-treated $\mathrm{rTg} 4510$ mice; $\mathrm{Tg}_{\mathrm{DFP}}=$ DFP-treated $\mathrm{rTg} 4510$ mice. $n=9 /$ group; $* p<0.05$; $* * p<0.001 ; * * * p<0.0001$ a

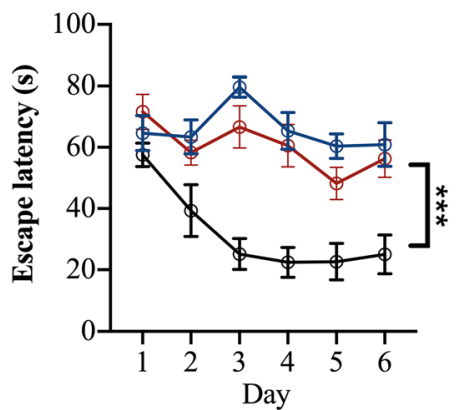

$\odot \mathbf{W T}_{\mathrm{SSV}} \odot \mathrm{Tg}_{\mathrm{SSV}} \odot \mathrm{Tg}_{\mathrm{DFP}}$

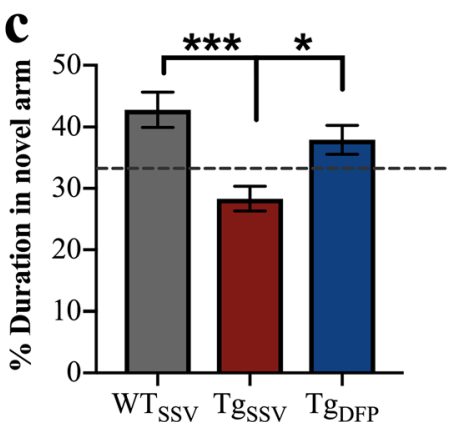

b
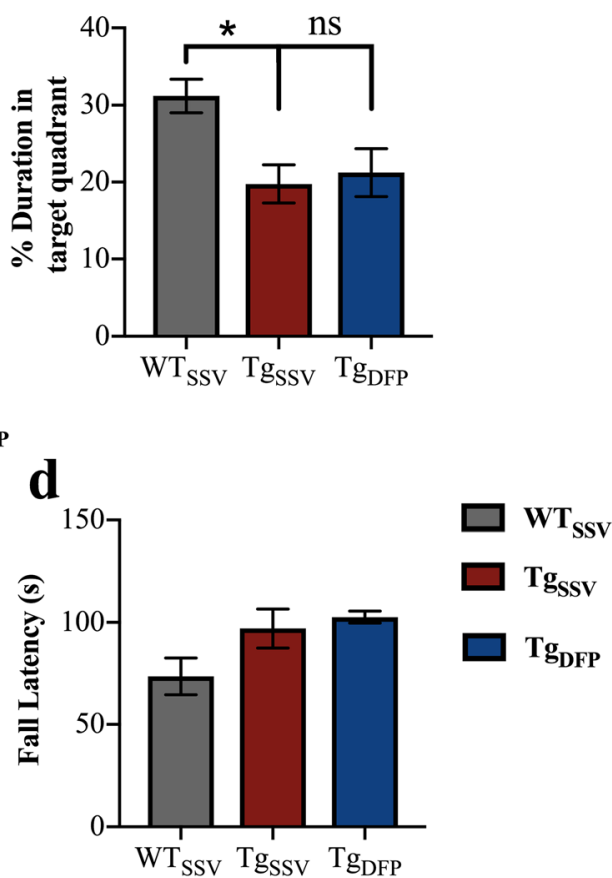


\section{Rotarod Performance Was Not Impaired in Tg Mice}

Motor coordination was measured using the rotarod test. There was no difference in performance between groups as measured by latency to fall (Fig. 1d).

\section{Spontaneous Locomotor Activity and Anxiety-Like Behavior Were Improved in DFP-Treated Mice}

Compared to WT mice, vehicle-treated $\mathrm{rTg} 4510$ mice covered seven times more distance in the 60-min period (Fig. 2a, $p<0.001)$. DFP decreased distance traveled by $40 \%$ in rTg4510 $(p<0.05)$, which may indicate a decrease in hyperactivity and anxiety-like behavior. Thigmotaxic behavior (walking along the walls of the chamber) is an indicator of anxiety in a new environment and is evident in rTg4510 mice. This phenotype can be measured by the duration spent in the outer zone of the chamber. Both WT and vehicle-treated rTg4510 mice spent more than $50 \%$ of the total trial period (60 min) in the outer zone (Fig. 2d), with WT mice spending significantly more time within the outer zone compared to vehicle-treated rTg4510 mice $(p<0.001)$. Upon further investigation, WT mice spent more time resting time and covered less distance (Fig. 2a, e), suggesting WT mice habituated to the environment over the trial period. Interestingly anxiolyticlike behavior (or time spent in the outer zone) was reduced by $21 \%$ in DFP-treated $\mathrm{rTg} 4510$ mice $(p<0.05)$. DFP also decreased walking speed (Fig. 2b) and rearing (Fig. 2c) by $42 \%$ and $52 \%$ compared to vehicle-treated $\mathrm{rTg} 4510$ mice ( $p<0.01$ and $p<0.05$, respectively), which may indicate exploratory behavior.

\section{DFP Treatment Reduces Brain Iron Levels and Increases Blood Plasma Iron}

Brain iron levels were measured using ICP-MS to examine the effect of DFP. Iron levels were increased by $40 \%$ in rTg 4510 mice compared to WT mice $(p<0.001)$ and were decreased by $28 \%$ following DFP treatment $(p<0.05$, Fig. 3a). Disruption in brain iron metabolism is reported to be reflected in the periphery [42]. In vehicle-treated rTg4510 mice, there was a $44 \%$ decrease in plasma iron levels compared to that WT mice (Fig. 3b, $p<0.05$ ). Interestingly, in DFP-treated mice, plasma iron levels were elevated by $34 \%$ compared to those in vehicle-treated rTg4510 mice $(p<0.05)$ and were not statistically different compared to those in WT mice.

\section{DFP Did Not Change the Quantity of Iron Associated with Metalloproteins}

To further examine the effect of DFP on iron, SEC-ICP-MS was employed to measure the amount of iron bound to metalloproteins such as ferritin (referred to as ferritin-iron). The chromatogram generated by SEC-ICP-MS revealed 3
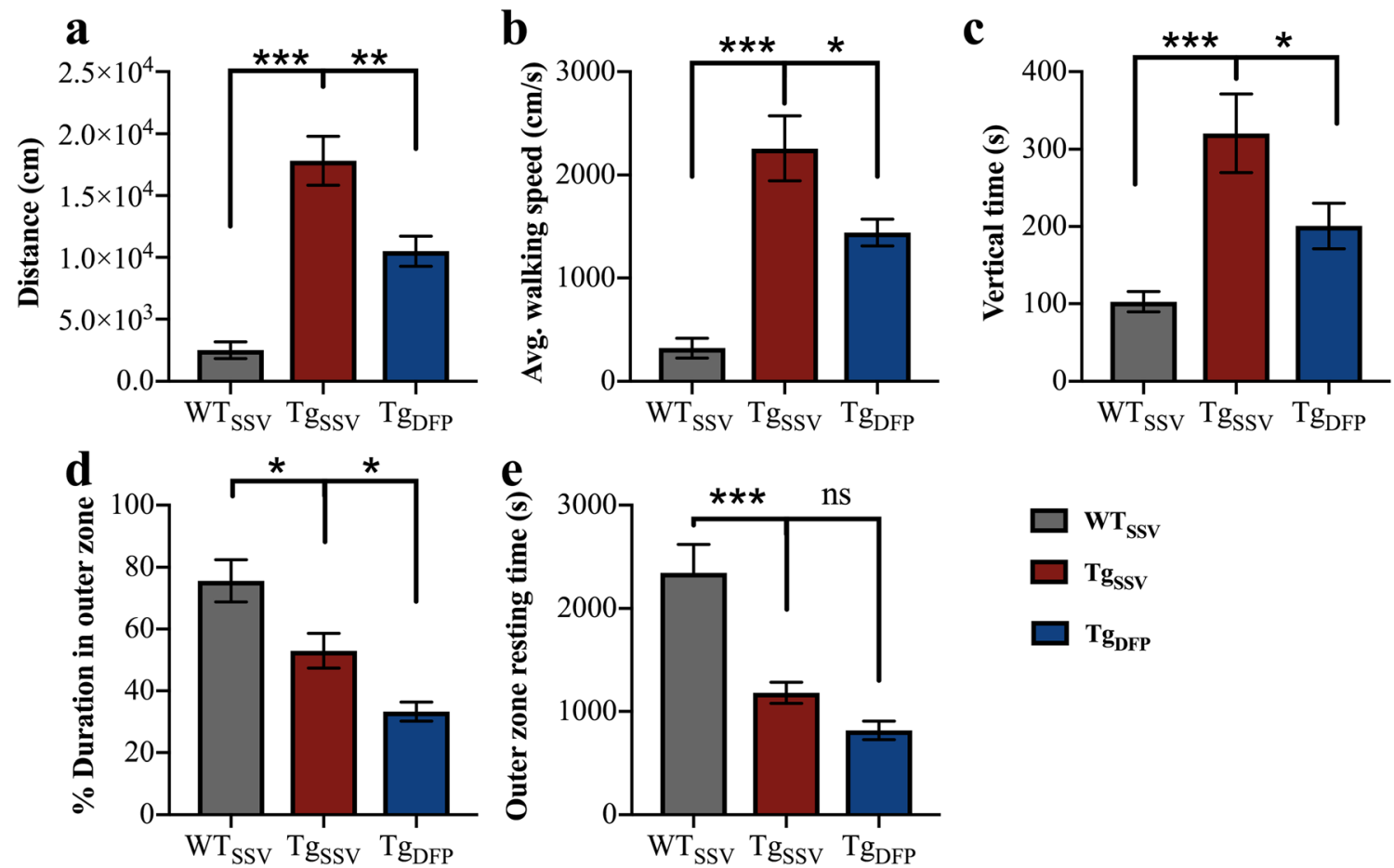

Fig. 2 Effects of DFP on locomotor and anxiety-like behavior. (a) Total distance traveled. (b) Walking speed. (c) Rearing (vertical time). (d) Duration spent in the outer zone. (e) Resting time within the outer. One-way ANOVA, Tukey's post hoc test. Error bars represent \pm SEM.

$\mathrm{WT}_{\mathrm{SSV}}=$ vehicle-treated $\mathrm{WT}$ mice; $\mathrm{Tg}_{\mathrm{SSV}}=$ vehicle-treated $\mathrm{rTg} 4510$ mice; $\mathrm{Tg}_{\mathrm{DFP}}=\mathrm{DFP}$-treated $\mathrm{rTg} 4510$ mice. $n=9 /$ group; $* p<0.05$; $* * p<0.001 ; * * * p<0.0001$ 

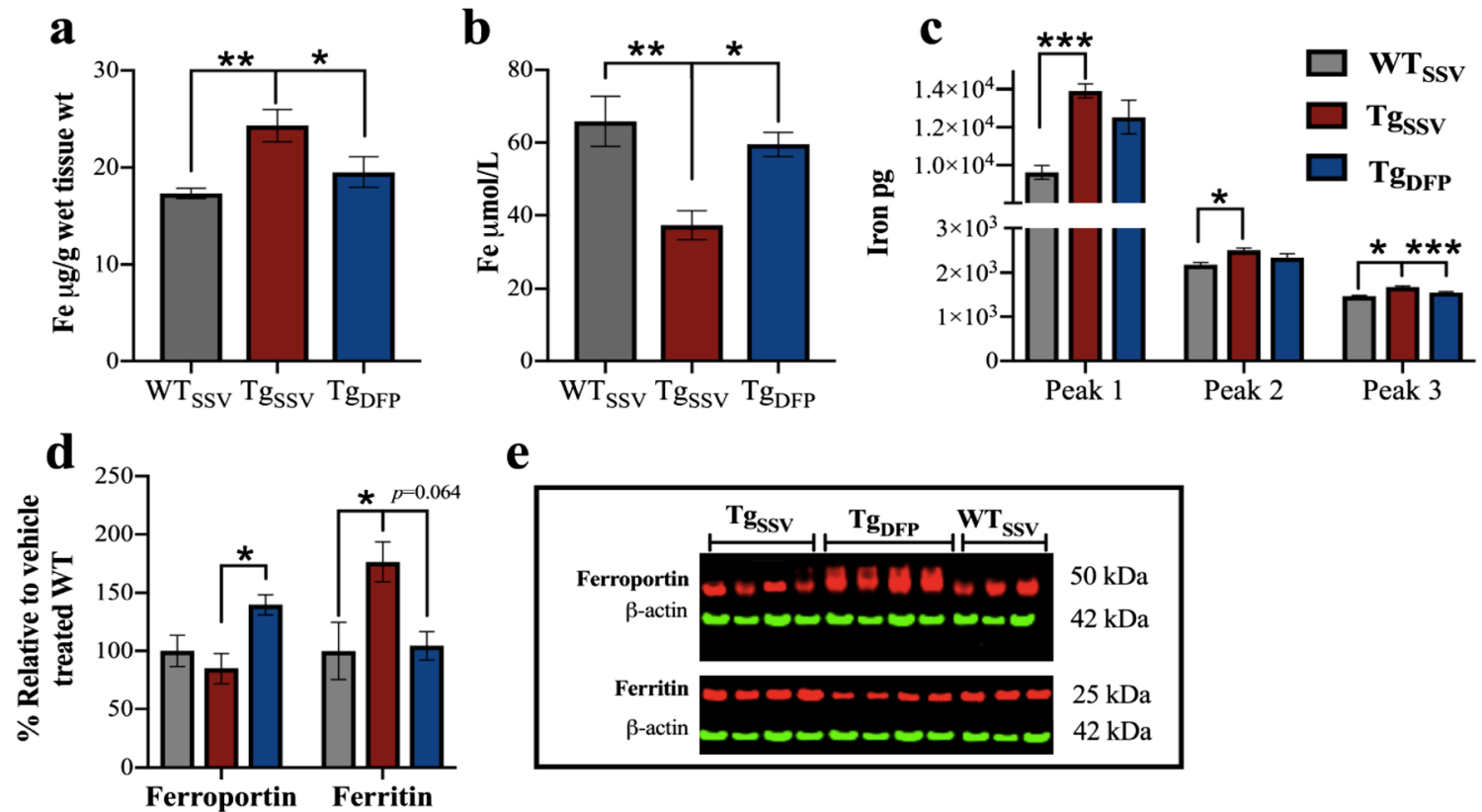

$\mathbf{e}$

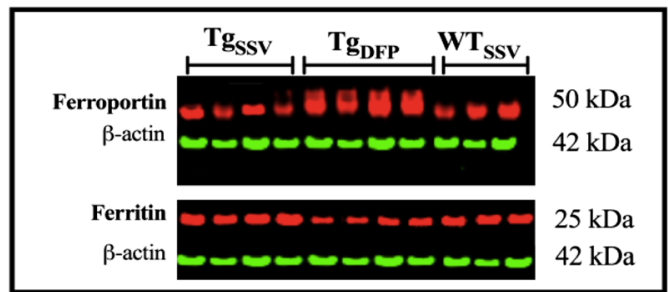

Fig. 3 Effects of DFP on iron. ICP-MS analysis was used to measure iron levels in (a) brain homogenates and in (b) blood plasma. (c) Iron bound to metalloproteins in brain homogenates was measured using SEC-ICP-MS. The area under the curve was averaged for each mouse within each group to examine iron content within each peak, which corresponds to the chromatogram shown in ESI Fig. S1. Peak 1 is associate with ferritinlike proteins; peak 2 may be associated with cytochrome c, and proteins associated with peak 3 are low molecular weight iron-protein complexes, which require further investigation. (d) Densitometry analysis normalized to $\beta$-actin of (e) representative western blot images of ferroportin, ferritin and $\beta$-actin in the hippocampus (note, antibodies were probed on the same blot). One-way ANOVA, Tukey's post hoc test. Error bars represent \pm SEM. $\mathrm{WT}_{\mathrm{SSV}}=$ vehicle-treated $\mathrm{WT}$ mice; $\mathrm{Tg}_{\mathrm{SSV}}=$ vehicletreated $\mathrm{rTg} 4510$ mice; $\mathrm{Tg}_{\mathrm{DFP}}=\mathrm{DFP}$-treated $\mathrm{rTg} 4510$ mice. $n=9 /$ group; $* p<0.05 ; * * p<0.001, * * * p<0.0001$ peaks (Fig. S1); based on previously published literature [41], peak 1 is most likely associated with ferritin and peak 2 may be associated with cytochrome $\mathrm{c}$. There was a $44 \%$ increase in ferritin-iron (Fig. 3b, $p<0.001$ ) and a $15 \%$ increase in iron potentially associated with cytochrome c (Fig. $3 \mathrm{~b}, p<0.001$ ) in rTg4510 mice compared to WT mice. Treatment with DFP did not change the amount of iron associated with these proteins. Iron associated with proteins within peak 3 was also significantly increased by $14 \%$ in rTg4510 mice compared to WT mice (Fig. $3 \mathrm{~b}, p<0.01$ ) and was decreased by $10 \%$ in DFP-treated mice $(p<0.001$, compared to vehicle-treated rTg4510 mice). However, further analysis is required to investigate the proteins associated with this peak.

\section{DFP Alters Iron-Associated Proteins}

Ferroportin is the only known iron exporter and plays a fundamental role in regulating cellular iron levels. Western blotting revealed no difference in ferroportin protein levels between WT and vehicle-treated rTg4510 mice (Fig. 3d, e). However, there was a $46 \%$ increase in ferroportin in DFPtreated $\mathrm{rTg} 4510$ mice compared to vehicle-treated $\mathrm{rTg} 4510$ mice $(p<0.05)$ and a $39 \%$ increase compared to WT mice $(p<0.05)$. Ferritin is the primary iron storage protein and is regulated by iron levels. There was a $76 \%$ increase in ferritin in vehicle-treated $\mathrm{rTg} 4510$ mice compared to WT mice (Fig. 3d, e; $p<0.05$ ), which was decreased by $41 \%$ in DFPtreated mice; however, this decrease did not reach statistical significance $(p=0.064)$.

\section{DFP Reduced AT8-Labeled Tau Counts in the Hippocampus}

The rTg4510 mouse model is driven by the overexpression of pathological tau, resulting in behavioral abnormalities and extensive tau pathology. The behavioral improvements that were observed in the Y-maze prompted examination of tau pathology following DFP treatment, using both histology to quantify AT8-labeled tau within the hippocampus and cortex and western blotting to assess tau phosphorylation patterns. Histological examination of rTg4510 brains revealed a $24 \%$ decrease in AT8-labeled tau following DFP treatment in rTg4510 mice within the hippocampus compared to vehicletreated mice (Fig. 4a, c; $p<0.05$ ). Within the cortex, there was a $15 \%$ decrease in AT8-labeled tau in DFP-treated mice, which was not statistically significant between treatment groups (Fig. 4a, c; $p>0.05$ ). Neuronal counts (NeuNpositive cells) were unchanged between treatment groups in the Tg mice (although there was the expected significant reduction in neurons in the Tg group as compared to WT mice; 


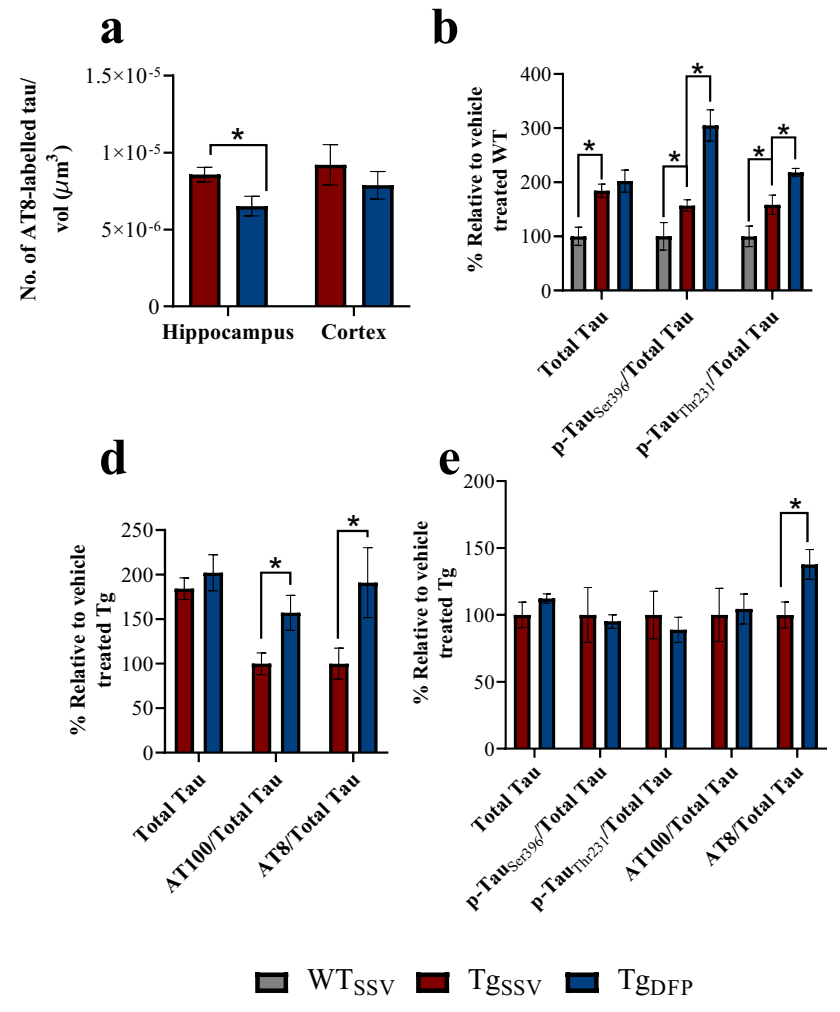

Fig. 4 Effects of DFP on tau pathology. a, $\mathbf{c}$ Stereological estimates of AT8-labeled tau in the hippocampus and cortex (2-tailed $t$ test). Ratios of $\mathrm{p}$-tau/total tau in soluble hippocampus fractions (b, one-way ANOVA, Tukey's post hoc test; d, 2-tailed t test). e, Ratios of p-tau/total tau in insoluble hippocampus fractions (2-tailed t test). f, Representative western blot images (note, some antibodies were probed on the same

data not shown). In order to understand the decrease in AT8labeled tau within the hippocampus, western blots of phosphorylated tau and proteins involved in this pathway were investigated.

\section{Increase in Soluble Phosphorylated Tau in DFP-Treated Mice}

Western blot analysis revealed an $84 \%$ increase in soluble total tau levels between rTg4510 and WT mice (Fig. 4b, $p<0.05$ ). No difference in total soluble tau levels was evident between $\mathrm{rTg} 4510$ treatment groups. Interestingly, there was an increase in tau phosphorylated at Ser396 $(+156 \%$, $p<0.05)$, Thr231 (+60\%, $p<0.05)$, AT100 (Ser212/ Thr214, $+57 \%, p<0.05)$, and AT8 $(+90 \%, p<0.05)$ within the soluble fractions relative to total tau in DFP-treated rTg4510 mice compared to vehicle-treated rTg4510 mice (Fig. 4b-f). In insoluble hippocampal fraction (Fig. 4e, f), there was an increase in AT8/total tau $(+36 \%, p<0.05)$ in DFP-treated rTg4510 mice. However, no difference was observed in tau phosphorylated at Ser396, Thr231, and AT100 relative to total tau levels. No tau was detected in WT mice. c
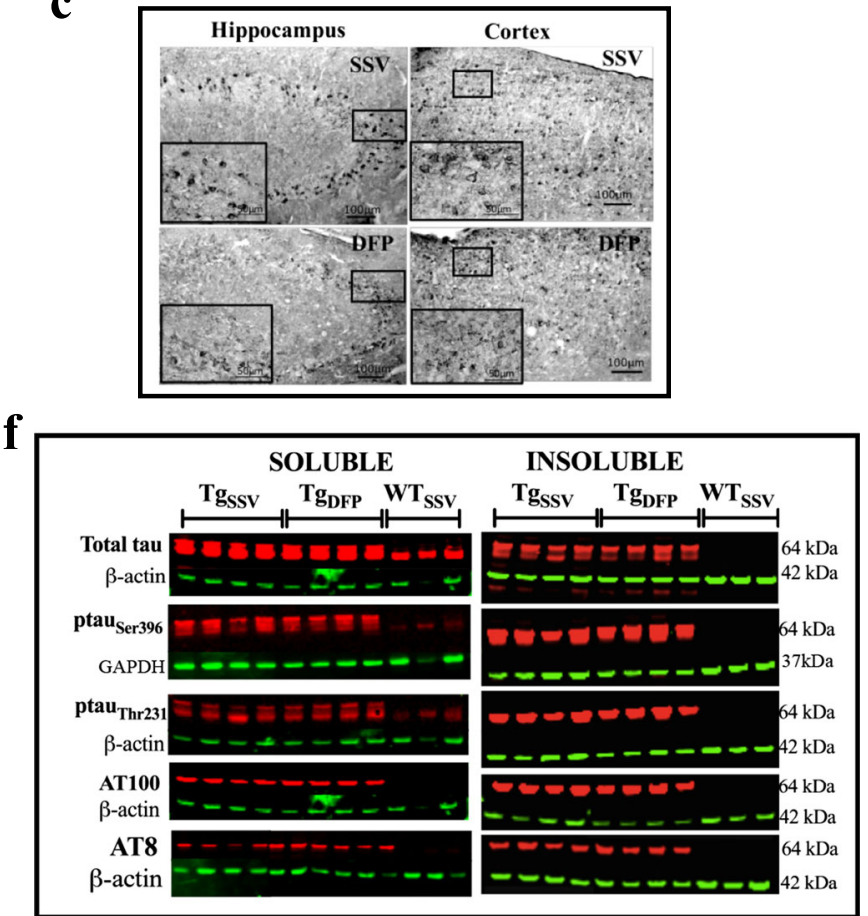

stripped blots used in Fig. 4 and Fig. 5) of total and p-tau in the hippocampus. Ratios of p-tau/total tau were determined using normalized $ß$-actin or GAPDH values. Error bars represent \pm SEM. TgSSV, vehicle-treated rTg4510 mice; TgDFP, DFP-treated rTg4510 mice. $\mathrm{n}=6 /$ group $; * p<0.05$

\section{DFP Downregulates GSK3 $\beta$ and CDK-5 in the Hippocampus}

Dysregulation of the tau kinases GSK3 $3 \beta$ and CDK5 is speculated to be a key factor in mediating tau pathology [43-46]. In addition, iron is reported to upregulate the activity of both kinases and promote tau hyperphosphorylation $[8,9,16,19]$. Total levels of GSK $3 \beta$ were unchanged between groups (Fig. $5 \mathrm{a}, \mathrm{c})$. The activity of GSK $3 \beta$ is negatively regulated by phosphorylation at Ser9 (p-GSK3 $\beta$ ) and was reduced by $27 \%$ in vehicle-treated $\mathrm{rTg} 4510$ mice compared to WT mice (Fig. $5 \mathrm{a}, \mathrm{c} ; p<0.001$ ). DFP increased $\mathrm{p}-\mathrm{GSK} 3 \beta$ by $43 \%$ in rTg4510 mice compared to vehicle-treated rTg4510 mice $(p<0.05)$. The ratio of $\mathrm{p}$-GSK3 $\beta$ relative to total levels of GSK $3 \beta$ was also assessed (Fig. 5a) and was decreased in vehicle-treated $\mathrm{rTg} 4510$ mice by $12 \%$ compared to WT mice $(p<0.05)$ and increased by $48 \%$ in DFP-treated mice ( $p<0.05$, compared to vehicle-treated $\mathrm{rTg} 4510$ mice). No changes in total CDK5 levels were evident between groups (Fig. 5a, c). However, phosphorylation of CDK5 at Tyr15, which upregulates kinase activity [47], was decreased by $49 \%$ in DFP-treated mice compared to vehicle-treated 


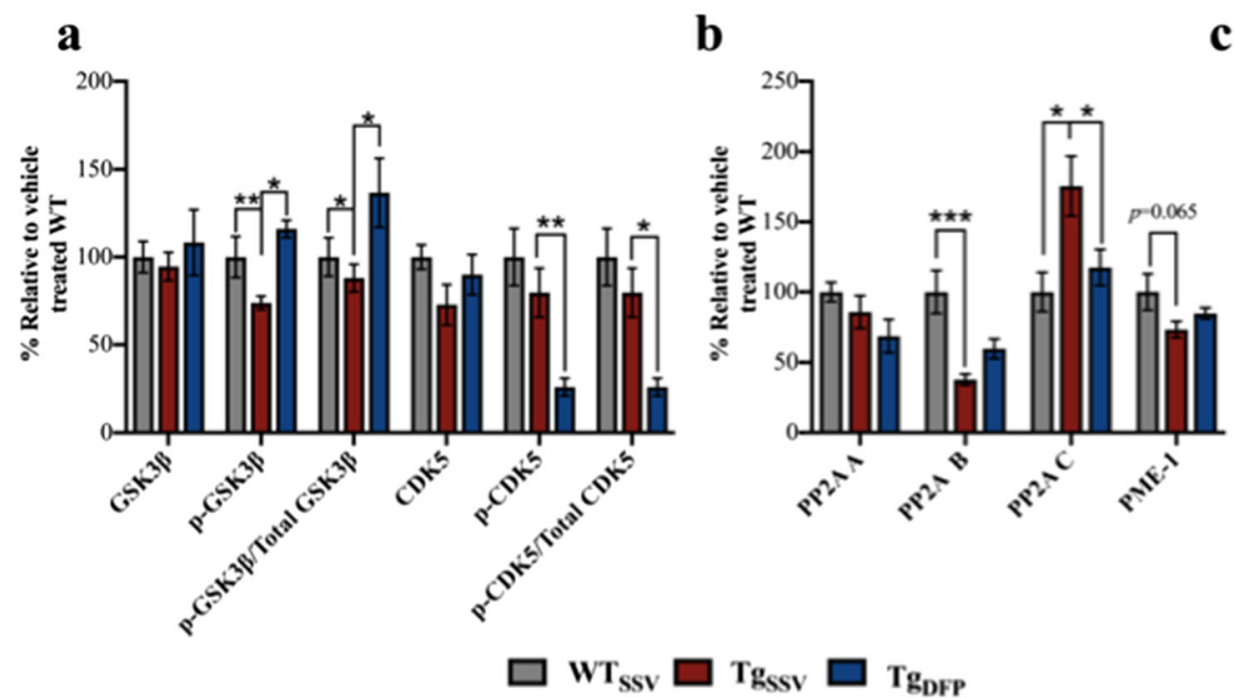

c

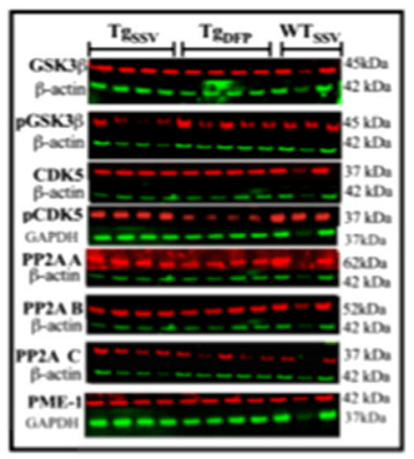

Fig. 5 Effects of DFP on tau phosphorylation pathways. (a, b) Densitometry analysis normalized to $\beta$-actin or GAPDH of (e) representative western blot images (note, some antibodies were probed on the same stripped blots used in Fig. 4 and Fig. 5) of total GSK3 $\beta$, pGSK3 $\beta$, total CDK5, pCDK5, PP2A A, PP2A B, PP2A C and PME-1.

Ratios of p-kinase/total kinase were determined using normalized ß-actin or GAPDH values. One-way ANOVA, Tukey's post hoc test. Error bars represent \pm SEM. $\mathrm{WT}_{\mathrm{SSV}}=$ Vehicle-treated $\mathrm{WT}$ mice; $\mathrm{Tg}_{\mathrm{SSV}}=$ vehicletreated $\mathrm{rTg} 4510 ; \mathrm{Tg}_{\mathrm{DFP}}=$ DFP-treated $\mathrm{rTg} 4510$ mice. $\mathrm{n}=9$ /group; ${ }^{*} p<0.05 ; * * p<0.001 ; * * * p<0.0001$

rTg4510 mice (Fig. 5a, c; $p<0.001$ ) and $64 \%$ compared to WT mice $(p<0.001)$. The ratio of $\mathrm{p}$-CDK5 to total CDK5 (Fig. 5a) between groups showed a similar decrease in DFPtreated mice compared to vehicle-treated $\mathrm{rTg} 4510(-53 \%$, $p<0.05)$ and WT $(-74 \%, p<0.05)$ mice. No difference in p-CDK5 relative to $\beta$-actin (Fig. 5a) or p-CDK5/total CDK5 (Fig. 5a) was evident between vehicle-treated rTg4510 and WT mice $(p>0.01)$.

\section{No Effect of DFP on PP2A}

The tau phosphatase - protein phosphatase 2A (PP2A)is a multi-subunit holoenzyme comprised of three subunits: the structural subunit A (PP2A A), regulatory subunit B (PP2A B), and catalytic subunit C (PP2A C). No difference in the level of subunit $A$ was observed between groups (Fig. $5 \mathrm{~b}, \mathrm{c} ; p>0.01$ ). Compared to WT, PP2A B was decreased by $63 \%$ in rTg 4510 mice (Fig. 5b, c; $p>0.001)$ and was not significantly increased following DFP treatment in rTg4510 mice. PP2A C was increased by $75 \%$ in vehicle-treated $\mathrm{rTg} 4510$ mice (Fig. 5b, c; $p<0.05$, compared to $\mathrm{WT}$ ) and was decreased by $58 \%$ in DFP-treated rTg4510 mice $(p<0.05)$. Regulation of PP2A occurs via several post-translational modifications that includes methylation (which promotes PP2A activity). The protein phosphatase methylesterase 1 (PME-1) catalyzes the demethylation of PP2A C and subsequently dampens PP2A activity. No statistical significance was evident between rTg4510 treatment groups in PME-1 (Fig. 5b, c).

\section{Discussion}

Brain iron levels are reported to accumulate in postmortem brains and in vivo imaging in PSP and $\mathrm{AD}$ in regions which accumulate tau pathology [6, 48, 49]. Using the $\mathrm{rTg} 4510$ mouse model of tauopathy, this study demonstrates the potential clinical benefits of targeting iron with DFP in the symptomatic stages of neurodegeneration. By 12 months, brain iron levels were increased by $40 \%$ in rTg4510 compared to agematched WT mice (Fig. 3a), which was reduced by $28 \%$ after 4 weeks of DFP treatment. This is consistent with outcomes from clinical trials in NBIA and PD patients, in which DFP is reported to reduce brain iron levels as measured by MRI [32]. Iron is abundant in the brain and is metabolically utilized as a cofactor due to its ability to redox cycle [50]. Iron metabolism is strictly regulated in the brain; the availability of iron for cellular processing is regulated by ferritin (which stores iron in its redox-inert state) and has a primary role in protecting against iron toxicity. In tauopathies, such as in PSP and AD, ferritin is significantly elevated compared to healthy controls $[23,24]$. While this increase may occur to compensate for the increase in brain iron levels, it is suggested that under pathological conditions, ferritin function may be impaired and that the iron stored within ferritin may contribute to oxidative damage [51]. Furthermore, in PSP, ferritin is reported to colocalize with tau in NFTs and ferritin-iron (iron stored within ferritin) is speculated to mediate tau aggregation [23]. DFP is reported to remove iron from ferritin [52], and it was hypothesized that reduced brain iron levels would also promote a decrease in ferritin and ferritin-iron levels. In $\mathrm{rTg} 4510$ mice, ferritin and 
iron associated with ferritin-like proteins were increased significantly compared to those in WT mice (Fig. 3b). However, there was only a trend towards a decrease in ferritin and ferritin-like iron in DFP-treated mice, which may suggest that a higher dose of DFP may be required for an effect or that a longer trial duration is required. Further, with SEC-ICP-MS analysis, while the use of metalloprotein standards, such as ferritin, can help identify proteins of interest, complex samples can have multiple proteins associated within one peak [41] and, therefore, the effects of DFP in our mouse model only provide an indication of how ferritin-iron may be altered. As our results indicated a decrease in brain iron levels, we then sort to examine the iron export pathway.

Ferroportin is the only known iron export protein and is downregulated in $\mathrm{AD}$ [53] and PD which may lead to cellular iron accumulation. Our results revealed no difference in ferroportin protein levels between WT and $\operatorname{rTg} 4510$, which may be due to the variations in signal intensities from western blotting (Fig. 3d, e). However, it may also suggest a possible pathway that is altered in normal aging that may contribute to physiological brain iron accumulation. Interestingly, DFP increased ferroportin in rTg4510 (Fig. 3d), possibly promoting cellular iron export. However, DFP treatment in rats following intracerebral hemorrhage (which is characterized by brain iron accumulation, oxidative stress, and neurological deficits) reduced brain iron levels, with no effect on ferroportin [54]. The different effects of DFP on ferroportin may be different due to the differences in the experimental designs between our study and that of Wang and colleagues [54] (see also), which include the animal model, treatment paradigm, and detection methods. Evidently, future studies are needed to explore the effect of DFP on the ferroportin iron export pathway in the brain to investigate the effects of DFP. Studies have reported that a disruption in brain iron metabolism is reflected in the periphery [42], leading us to examine plasma iron levels.

The Australian Imaging, Biomarkers and Lifestyle Flagship Study of Ageing (AIBL) reported decreased plasma iron levels in AD compared to healthy controls [42]. Similarly, in rTg4510, ICP-MS analysis of blood plasma samples revealed a significant decrease in plasma iron compared to that in WT mice (Fig. 3b), which was elevated with DFP. Deficiency in plasma iron is reported to be a result of inadequate iron loading onto transferrin (Tf) in $\mathrm{AD}[42,55]$. Future experiments will need to assess the effect of DFP in plasma samples in rTg4510 to gain a better understanding of the mechanisms of DFP and to examine iron levels in other areas (such as liver and kidney) in rtg4510 mice to explore how DFP may impact overall iron metabolism.

Iron dysregulation is well established to have significant implications in motor and cognitive functions [14-20]. Chelation of iron in various animal models of neurodegeneration such as $\mathrm{AD}$ [20] and $\mathrm{PD}$ [56] and of neurodegeneration induced by iron [14] and in tau KO mouse models [57] is reported to improve cognitive and motor functions. Intranasal administration of deferoxamine (an iron chelator) improved performance in the radial arm maze in tau transgenic mice (JNPL $3_{\text {tauP301L }}$ ) [15] and reversed spatial memory impairment in APP/PSI transgenic mice [20]. Interestingly, other compounds such as metal chaperones that include clioquinol - which deliver/redistribute metals such as copper and zinc - are reported to improve spatial reference memory in aged tau knockout mice [17, 58]. While no drug effect was observed in the MWM in rTg4510 mice in this study (Fig. 1a, b), DFP did improve performance in Y-maze, which may indicate an improvement in short-term memory function and normalized exploratory behavior (Fig. 1c). However, one of the limitations of this study was that we were unable to examine the effects of DFP on spontaneous alternations in Y-maze. The effect of DFP on memory deficits is sparse in the literature, though several studies have reported that DFP rescues recognition memory deficits $[14,56]$ and improves spatial learning in the MWM [34]. Interestingly, Sripetchwandee and colleagues [34] used a lower dosage of DFP $(50 \mathrm{mg} / \mathrm{kg})$ in conjunction with an antioxidant, suggesting that the efficacy of DFP maybe more robust in combination therapy.

In addition to memory loss, patients with $\mathrm{AD}$ and FTD experience behavioral symptoms such as agitation, anxiety, wandering behavior, and hyperactivity $[59,60]$. The rTg4510 mice exhibit high levels of locomotor hyperactivity and anxiety-like behavior [61]. This phenotype is also a common feature in other transgenic tau models $[62,63]$ and is associated with amygdala function. Treatment with DFP reduced hyperactivity (Fig. 2a, b) and thigmotaxic behavior (Fig. 2d) in $\mathrm{rTg} 4510$ mice. The CaMKII $\alpha$ promoter can drive transgene overexpression in the amygdala [64, 65]. This has been verified in the rTg4510 mouse model, and deficits in amygdala exploratory behavior are found to correlate with the accumulation of NFTs [66]. However, while thigmotaxis is reported to be a measure of anxiety [67, 68], the open field test only provides an indication of anxietylike behavior. Therefore, future experiments using dark/ light exploration tests should be used to examine the effect of DFP on anxiety and NFTs within the amygdala. Based on this association between anxiety and tangle accumulation, it is hypothesized that DFP may reduce NFTs within this region.

One of the limitations of this study was that we were unable to examine any gender-dependent effects of DFP, which may have been informative, given that studies have demonstrated significant sex differences in cognitive function and spontaneous locomotor activity in $\mathrm{rTg} 4510$ mice $[61,69]$. Our analysis did show that there were subtle differences between genders in locomotor activity and Y-maze (Fig. S2); however, due the size of the treatment groups and the availability of animals to perform this 
study, further studies are required to elucidate how DFP may affect behavioral phenotypes within genders.

Histological analysis of AT8-labeled tau (which is associated with late stages of tangle formation) was examined in the hippocampal and cortical regions of the brain (Fig. 4a), as these regions are primarily affected in AD. Stereological assessment of both regions revealed a significant decrease in AT8-labeled tau in the hippocampus. However, no drug effect was observed in the cortex on AT8-labeled tau. As iron is speculated to act as a cofactor for tau hyperphosphorylation and subsequent NFT formation, this may suggest that the consequences of iron dysregulation in the hippocampus are more severe than those in the cortex and DFP may reduce iron levels within this region. DFP is reported to target iron in a regionspecific manner [31, 32, 70]. In clinical trials, DFP reduced iron content within the substantia nigra in PD patients, while no other regions were affected $[32,70]$. Perls Prussian blue staining was attempted to examine regional iron levels in rTg4510 brain sections in this study, though there were no visually apparent regions of positive staining. Future experiments employing laser ablation ICP-MS or enhanced Perls Prussian blue staining could be used to quantify the regional distribution of iron to investigate the region-specific effect of DFP hippocampal iron levels that may have led to a decrease in AT8-labeled tau.

To elucidate the mechanisms underlying the decrease in AT8-labeled tau inclusions, tau phosphorylation patterns were investigated in the hippocampus (Fig. 4). Tau phosphorylated at Ser396, Thr231, and Th212/Ser214 is critical for NFT formation $[71,72]$. While total soluble tau levels were unchanged between groups (Fig. 4b), there was an increase in soluble tau phosphorylated at Ser396, Thr231, AT100, and AT8 relative to total tau in DFP-treated mice compared to vehicle-treated mice. A shift in an increase in soluble tau species (specifically phosphorylated tau at Ser396/404) has been reported in JNPL3 $3_{(\text {tauP301L) }}$ mice following active immunization with phosphorylated tau epitopes accompanied with improved motor performance (which is a prominent deficit in JNPL3 ${ }_{(\operatorname{tauP301L})}$ [73]. However, there were no deficits in short-term memory function in JNPL3 $3_{(\text {tauP301L) }}$ at the time of behavioral testing as measured by the object recognition task [73]. Studies have demonstrated that the accumulation of hyperphosphorylated soluble tau is critical for the formation and accumulation of NFTs, correlating with symptomatic decline $[74,75]$. Therefore, it was quite surprising to see an increase in tau phosphorylation and improved short-term memory function in rTg4510 (Fig. 1c). As iron is reported to bind to tau and potentially induce conformation changes of the protein and subsequent aggregation [7, 22, 28], we hypothesize that the chelation of iron with DFP may prevent interactions between iron and tau and avert NFT formation or DFP may remove iron from NFTs, reversing or "untangling" tau, possibly leading to an increase in soluble phosphorylated tau.
This untangling or disassociation of iron from NFTs has been demonstrated with the iron chelator deferoxamine ex vivo in AD tissue samples [7, 22], leading to a shift in soluble tau. DFP has a relatively short half-life of approximately 47 134 min [76], which may suggest that short-term DFP treatment requires multiple daily dosing to promote a decrease in tau phosphorylation or that a longer trial duration is required to observe a decrease in tau phosphorylation. In our previous study [37], we observed a decrease in tau phosphorylation after 4 months of DFP treatment $(100 \mathrm{mg} / \mathrm{kg} /$ daily $)$ in 7-8month-old rTg4510 mice. Evidently, further studies are required to examine the long-term effects in aged $\mathrm{rTg} 4510$ mice and the effects of various dosing regimens on behavior and tau pathology. To further elucidate the increase in tau phosphorylation patterns in our mouse model, we next investigated the tau phosphorylation pathways.

The tau kinases GSK3 $\beta$ and CDK5 are both associated with tau hyperphosphorylation [77, 78] and are upregulated in the presence of iron, potentially inducing tau hyperphosphorylation $[8,9,79,80]$. While the increase in tau phosphorylation could have been hypothesized to be driven by alterations in GSK3 $\beta$ and CDK5, DFP downregulated both kinases (Fig. 5a). Given that we demonstrated an ironlowering effect of DFP in this study, these data are consistent with previous in vitro and in vivo literature showing that the chelation of iron with DFP and other iron chelators $[15,16$, 33] downregulates both kinases. Further work is required to understand what may contribute to increased tau phosphorylation. However, it is hypothesized that other tau kinases may be involved in the process that requires investigation such as mitogen-activated protein kinase (MAPK) and calmodulindependent protein kinases, like GSK $3 \beta$ and CDK5, are proline-directed kinases, which phosphorylate Ser and Thr residues of tau in tauopathies. Examination of the tau phosphatase PP2A, which accounts for $\sim 70 \%$ of tau dephosphorylation and is downregulated in $\mathrm{AD}$ [81, 82], revealed that DFP decreased PP2A C (catalytic subunit) in rTg4510 (Fig. 5b) but did not alter protein levels of subunits A and B (Fig. 5b). Examination of PME-1 (which is associated with the demethylation of the catalytic subunit and dampens the activity of PP2A) revealed a trend towards a decrease in PME-1 in rTg4510 compared to vehicle control (Fig. 5b), though there was no difference in PME-1 between rTg4510 treatment groups. Our results suggest that DFP may have little effect of PP2A protein levels in the short term and may indicate why there was no decrease in tau phosphorylation. Furthermore, the phosphorylation of tau at Thr231 inhibits PP2A and tau interactions [83], which may lead to decreases in the catalytic subunit, resulting in high levels of soluble phosphorylated tau. Future studies should employ enzyme activity assays to elucidate the effect of DFP on PP2A activity. This will complement the protein studies performed here and will contribute to our understanding of the interaction between 
tau and DFP (the decrease in PP2A C protein observed here may help explain the increase in soluble p-tau caused by DFP if it is also translated to a change in phosphatase activity). Collectively, this data demonstrates the low impact of DFP in the short term on tau phosphorylation pathways and further studies may need to employ a more chronic DFP treatment paradigm.

\section{Conclusion}

Taken together, this data demonstrates the short-term therapeutic efficacy of DFP in aged $\mathrm{rTg} 4510$ mice and the potential benefits of iron chelation in the symptomatic stages of neurodegeneration. Over the short duration, DFP improved behavioral deficits in the Y-maze and reduced NFTs within the hippocampus. However, there are still several pathways and mechanisms of DFP that warrant further investigation. Importantly, this data suggests that intervention with DFP may be effective in slowing down disease progression in tauopathies.

Supplementary Information The online version contains supplementary material available at https://doi.org/10.1007/s13311-020-00972-w.

Acknowledgments The Florey Institute of Neuroscience and Mental Health acknowledge the strong support from the Victorian Government and, in particular, the funding from the Operational Infrastructure Support Grant. The authors would like to thank Blaine Roberts and the Neuroproteomics Facility (Florey) for the use of the SEC-ICP-MS equipment. SSR would also like to thank the Core Animal Services staff and other members of the Florey and the Melbourne Dementia Research Centre for their assistance throughout the project, and SSR was supported by a Parkinson's Victoria—Argyrou Family PhD Partner Scholarship.

\section{Compliance with Ethical Standards}

Disclosures PAA and DIF are shareholders and paid consultants to Alterity Therapeutics which design compounds to target metal ions for the purpose of treating neurodegenerative diseases. This company had no input into this manuscript.

\section{References}

1. Braak H, Braak E. Neuropathological stageing of Alzheimerrelated changes. Acta Neuropathologica. 1991;82(4):239-59.

2. Grundke-Iqbal I, Iqbal K, Tung YC, Quinlan M, Wisniewski HM, Binder LI. Abnormal phosphorylation of the microtubuleassociated protein tau (tau) in Alzheimer cytoskeletal pathology. Proceedings of the National Academy of Sciences of the United States of America 83, 4913-4917 (1986).

3. Huber CM, Yee C, May T, Dhanala A, Mitchell CS. Cognitive Decline in Preclinical Alzheimer's Disease: Amyloid-Beta versus Tauopathy. Journal of Alzheimer's Disease: JAD. 2018;61(1):26581.

4. Lowe, V. J., Wiste, H. J., Senjem, M. L., Weigand, S. D., Therneau, T. M., Boeve, B. F., ... \& Kantarci, K. (2018). Widespread brain tau and its association with ageing, Braak stage and Alzheimer's dementia. Brain, 141(1), 271-287.

5. Borna H, Assadoulahei K, Riazi G, Harchegani AB, Shahriary A. Structure, Function and Interactions of Tau: Particular Focus on Potential Drug Targets for the Treatment of Tauopathies. CNS Neurol Disord Drug Targets. 2018;17(5):325-37.

6. Bulk M, Kenkhuis B, van der Graaf LM, Goeman JJ, Natte R, van der Weerd L. Postmortem T2*- Weighted MRI Imaging of Cortical Iron Reflects Severity of Alzheimer's Disease. Journal of Alzheimer's Disease: JAD. 2018;65(4):1125-37.

7. Yamamoto A, Shin RW, Hasegawa K, Naiki H, Sato H, Yoshimasu $\mathrm{F}$, et al. Iron (III) induces aggregation of hyperphosphorylated tau and its reduction to iron (II) reverses the aggregation: implications in the formation of neurofibrillary tangles of Alzheimer's disease. Journal of Neurochemistry. 2002;82(5):1137-47.

8. Bautista E, Vergara P, Segovia J. Iron-induced oxidative stress activates AKT and ERK1/2 and decreases Dyrk1B and PRMT1 in neuroblastoma SH-SY5Y cells. J Trace Elem Med Biol. 2016;34:62-9.

9. Egana JT, Zambrano C, Nunez MT, Gonzalez-Billault C, Maccioni RB. Iron-induced oxidative stress modify tau phosphorylation patterns in hippocampal cell cultures. Biometals: an International Journal on the Role of Metal Ions in Biology, Biochemistry, and Medicine. 2003;16(1):215-23.

10. van Duijn S, Bulk M, van Duinen SG, Nabuurs RJA, van Buchem MA, van der Weerd L, et al. Cortical Iron Reflects Severity of Alzheimer's Disease. Journal of Alzheimer's Disease: JAD. 2017;60(4):1533-45.

11. Hare, D. J., Lei, P., Ayton, S., Roberts, B. R., Grimm, R., George, J. L., Bishop, D. P., Beavis, A. D., Donovan, S. J., McColl, G., Volitakis, I., Masters, C. L., Adlard, P. A., Cherny, R. A., Bush, A. I., Finkelstein, D. I. \& Doble, P. A. An iron-dopamine index predicts risk of parkinsonian neurodegeneration in the substantia nigra pars compacta. Chemical Science 5, 2160-2169 (2014).

12. Daugherty AM, Raz N. Appraising the Role of Iron in Brain Aging and Cognition: Promises and Limitations of MRI Methods. Neuropsychol Rev. 2015;25(3):272-87.

13. Schneider SA, Hardy J, Bhatia KP. Syndromes of neurodegeneration with brain iron accumulation (NBIA): an update on clinical presentations, histological and genetic underpinnings, and treatment considerations. Movement Disorders: Official Journal of the Movement Disorder Society. 2012;27(1):42-53.

14. Alcalde LA, de Freitas BS, Machado GDB, de Freitas Crivelaro PC, Dornelles VC, Gus H, et al. Iron chelator deferiprone rescues memory deficits, hippocampal BDNF levels and antioxidant defenses in an experimental model of memory impairment. Biometals: an International Journal on the Role of Metal Ions in Biology, Biochemistry, and Medicine. 2018;31(6):927-40.

15. Fine J, Baillargeon A, Renner D, Hoerster N, Tokarev J, Colton S, et al. Intranasal deferoxamine improves performance in radial arm water maze, stabilizes HIF- $1 \alpha$, and phosphorylates GSK $3 \beta$ in P301L tau transgenic mice. Experimental Brain Research. 2012;219(3):381-90.

16. Xie L, Zheng W, Xin N, Xie JW, Wang T, Wang ZY. Ebselen inhibits iron-induced tau phosphorylation by attenuating DMT1 up-regulation and cellular iron uptake. Neurochemistry International. 2012;61(3):334-40.

17. Lei P, Ayton S, Finkelstein DI, Spoerri L, Ciccotosto GD, Wright DK, et al. Tau deficiency induces parkinsonism with dementia by impairing APP-mediated iron export. Nature Medicine. 2012;18(2): 291-5.

18. Lei P, Ayton S, Moon S, Zhang Q, Volitakis I, Finkelstein DI, et al. Motor and cognitive deficits in aged tau knockout mice in two background strains. Molecular Neurodegeneration. 2014;9:29.

19. Guo C, Wang P, Zhong ML, Wang T, Huang XS, Li JY, et al. Deferoxamine inhibits iron induced hippocampal tau 
phosphorylation in the Alzheimer transgenic mouse brain. Neurochemistry International. 2013;62(2):165-72.

20. Guo C, Wang T, Zheng W, Shan ZY, Teng WP, Wang ZY. Intranasal deferoxamine reverses iron-induced memory deficits and inhibits amyloidogenic APP processing in a transgenic mouse model of Alzheimer's disease. Neurobiology of Aging. 2013;34(2): 562-75.

21. Ayton, S., Wang, Y., Diouf, I., Schneider, J. A., Brockman, J., Morris, M. C., \& Bush, A. I. (2019). Brain iron is associated with accelerated cognitive decline in people with Alzheimer pathology. Molecular psychiatry. 2020;25(11):2932-2941.

22. Smith MA, Harris PL, Sayre LM, Perry G. Iron accumulation in Alzheimer disease is a source of redox-generated free radicals. Proceedings of the National Academy of Sciences of the United States of America. 1997;94(18):9866-8.

23. Perez M, Valpuesta, J.M., de Garcini, E.M., Quintana, C., Arrasate, M., Carrascosa, J.L., Rábano, A., de Yebenes, J.G. and Avila, J. Ferritin is associated with the aberrant tau filaments present in progressive supranuclear palsy. The American Journal of Pathology. 1998;152(6).1531-9.

24. Jellinger K, Paulus W, Grundke-Iqbal I, Riederer P, Youdim MB. Brain iron and ferritin in Parkinson's and Alzheimer's diseases. Journal of Neural Transmission Parkinson's Disease and Dementia Section. 1990;2(4):327-40.

25. Connor JR, Menzies SL, St Martin SM, Mufson EJ. A histochemical study of iron, transferrin, and ferritin in Alzheimer's diseased brains. Journal of Neuroscience Research. 1992;31(1):75-83.

26. Grundke-Iqbal I, Fleming J, Tung YC, Lassmann H, Iqbal K, Joshi JG. Ferritin is a component of the neuritic (senile) plaque in Alzheimer dementia. Acta Neuropathologica. 1990;81(2):105-10.

27. LeVine SM. Iron deposits in multiple sclerosis and Alzheimer's disease brains. Brain Research. 1997;760(1-2):298-303.

28. Ahmadi S, Ebralidze, I. I., She, Z., \& Kraatz, H. B. Electrochemical studies of tau protein-iron interactions - Potential implications for Alzheimer's Disease. Electrochimica Acta. 2017;236:384-93.

29. Hider RC, Roy S, Ma YM, Le Kong X, Preston J. The potential application of iron chelators for the treatment of neurodegenerative diseases. Metallomics: Integrated Biometal Science. 2011;3(3): 239-49.

30. Cohen AR, Galanello R, Piga A, De Sanctis V, Tricta F. Safety and effectiveness of long-term therapy with the oral iron chelator deferiprone. Blood. 2003;102(5):1583-7.

31. Velasco-Sanchez D, Aracil A, Montero R, Mas A, Jimenez L, O'Callaghan M, et al. Combined therapy with idebenone and deferiprone in patients with Friedreich's ataxia. Cerebellum. 2011;10(1):1-8.

32. Devos D, Moreau C, Devedjian JC, Kluza J, Petrault M, Laloux C, et al. Targeting chelatable iron as a therapeutic modality in Parkinson's disease. Antioxidants \& Redox Signaling. 2014;21(2): 195-210.

33. Prasanthi JR, Schrag M, Dasari B, Marwarha G, Dickson A, Kirsch WM, et al. Deferiprone reduces amyloid-beta and tau phosphorylation levels but not reactive oxygen species generation in hippocampus of rabbits fed a cholesterol-enriched diet. Journal of Alzheimer's Disease: JAD. 2012;30(1):167-82.

34. Sripetchwandee J, Pipatpiboon N, Chattipakorn N, Chattipakorn S. Combined therapy of iron chelator and antioxidant completely restores brain dysfunction induced by iron toxicity. PLoS One. 2014;9(1):e85115.

35. Santacruz K, Lewis J, Spires T, Paulson J, Kotilinek L, Ingelsson $\mathrm{M}$, et al. Tau suppression in a neurodegenerative mouse model improves memory function. Science. 2005;309(5733):476-81.

36. Ramsden M, Kotilinek L, Forster C, Paulson J, McGowan E, SantaCruz K, et al. Age-dependent neurofibrillary tangle formation, neuron loss, and memory impairment in a mouse model of human tauopathy (P301L). The Journal of Neuroscience: the Official Journal of the Society for Neuroscience. 2005;25(46):10637-47.

37. Rao SS, Lago L, Gonzalez de Vega R, Bray L, Hare DJ, Clases D, et al. Characterising the spatial and temporal brain metal profile in a mouse model of tauopathy. Metallomics: Integrated Biometal Science. 2020;12(2):301-13.

38. Sedjahtera A, Gunawan L, Bray L, Hung LW, Parsons J, Okamura N, Villemagne VL, Yanai K, Liu XM, Chan J, Bush AI, Finkelstein DI, Barnham KJ, Cherny RA, Adlard PA. Targeting metals rescues the phenotype in an animal model of tauopathy. Metallomics: 10, 1339-1347 (2018).

39. Maynard CJ, Cappai R, Volitakis I, Cherny RA, Masters CL, Li QX, et al. Gender and genetic background effects on brain metal levels in APP transgenic and normal mice: implications for Alzheimer beta-amyloid pathology. Journal of Inorganic Biochemistry. 2006;100(5-6):952-62.

40. Hoppler, M., Schonbachler, A., Meile, L., Hurrell, R.F. \& Walczyk, $\mathrm{T}$. Ferritin-iron is released during boiling and in vitro gastric digestion. The Journal of nutrition 138, 878-884 (2008).

41. Lothian A, Roberts BR. Standards for Quantitative Metalloproteomic Analysis Using Size Exclusion ICP-MS. J Vis Exp. 2016;(110):53737.

42. Faux NG, Rembach A, Wiley J, Ellis KA, Ames D, Fowler CJ, et al. An anemia of Alzheimer's disease. Molecular Psychiatry. 2014;19(11):1227-34.

43. Pei JJ, Grundke-Iqbal I, Iqbal K, Bogdanovic N, Winblad B, Cowburn RF. Accumulation of cyclin-dependent kinase 5 (cdk5) in neurons with early stages of Alzheimer's disease neurofibrillary degeneration. Brain Research. 1998;797(2):267-77.

44. Sengupta A, Kabat J, Novak M, Wu Q, Grundke-Iqbal I, Iqbal K. Phosphorylation of tau at both Thr 231 and Ser 262 is required for maximal inhibition of its binding to microtubules. Archives of Biochemistry and Biophysics. 1998;357(2):299-309.

45. Wang JZ, Wu Q, Smith A, Grundke-Iqbal I, Iqbal K. Tau is phosphorylated by GSK-3 at several sites found in Alzheimer disease and its biological activity markedly inhibited only after it is prephosphorylated by A-kinase. FEBS Letters. 1998;436(1):28-34.

46. Liu F, Grundke-Iqbal I, Iqbal K, Gong CX. Contributions of protein phosphatases PP1, PP2A, PP2B and PP5 to the regulation of tau phosphorylation. European Journal of Neuroscience. 2005;22(8): 1942-50.

47. Zukerberg LR, Patrick GN, Nikolic M, Humbert S, Wu CL, Lanier LM, et al. Cables links Cdk5 and c-Abl and facilitates Cdk5 tyrosine phosphorylation, kinase upregulation, and neurite outgrowth. Neuron. 2000;26(3):633-46.

48. Smith MA, Zhu X, Tabaton M, Liu G, McKeel DW, Jr., Cohen $\mathrm{ML}$, et al. Increased iron and free radical generation in preclinical Alzheimer disease and mild cognitive impairment. Journal of Alzheimer's Disease: JAD. 2010;19(1):363-72.

49. Boelmans K, Holst B, Hackius M, Finsterbusch J, Gerloff C, Fiehler J, et al. Brain iron deposition fingerprints in Parkinson's disease and progressive supranuclear palsy. Movement Disorders. 2012;27(3):421-7

50. Nunez MT, Urrutia P, Mena N, Aguirre P, Tapia V, Salazar J. Iron toxicity in neurodegeneration. Biometals: an International Journal on the Role of Metal Ions in Biology, Biochemistry, and Medicine. 2012;25(4):761-76.

51. Quintana C, Gutierrez L. Could a dysfunction of ferritin be a determinant factor in the aetiology of some neurodegenerative diseases? Biochimica et biophysica acta. 2010;1800(8):770-82.

52. Crisponi G, Nurchi VM, Crespo-Alonso M, Sanna G, Zoroddu MA, Alberti G, et al. A Speciation Study on the Perturbing Effects of Iron Chelators on the Homeostasis of Essential Metal Ions. PLoS One. 2015;10(7):e0133050.

53. Raha AA, Vaishnav RA, Friedland RP, Bomford A, RahaChowdhury R. The systemic iron-regulatory proteins hepcidin 
and ferroportin are reduced in the brain in Alzheimer's disease. Acta Neuropathologica Communications. 2013;1:55.

54. Wang G, Hu W, Tang Q, Wang L, Sun XG, Chen Y, et al. Effect Comparison of Both Iron Chelators on Outcomes, Iron Deposit, and Iron Transporters After Intracerebral Hemorrhage in Rats. Molecular Neurobiology. 2016;53(6):3576-85.

55. Hare DJ, Doecke JD, Faux NG, Rembach A, Volitakis I, Fowler CJ, et al. Decreased plasma iron in Alzheimer's disease is due to transferrin desaturation. ACS Chem Neurosci. 2015;6(3):398-402.

56. Carboni E, Tatenhorst L, Tonges L, Barski E, Dambeck V, Bahr M, et al. Deferiprone Rescues Behavioral Deficits Induced by Mild Iron Exposure in a Mouse Model of Alpha-Synuclein Aggregation. Neuromolecular Medicine. 2017;19(2-3):309-21.

57. Kaur D, Yantiri F, Rajagopalan S, Kumar J, Mo JQ, Boonplueang $\mathrm{R}$, Viswanath V, Jacobs R, Yang L, Beal MF, DiMonte D, Volitaskis I, Ellerby L, Cherny RA, Bush AI, Andersen JK. Genetic or pharmacological iron chelation prevents MPTPinduced neurotoxicity in vivo: a novel therapy for Parkinson's disease. Neuron. 37(6):899-909 (2003).

58. Lei P, Ayton S, Appukuttan AT, Volitakis I, Adlard PA, Finkelstein DI, et al. Clioquinol rescues Parkinsonism and dementia phenotypes of the tau knockout mouse. Neurobiology of Disease. 2015;81:168-75

59. Rolland Y, Andrieu S, Cantet C, Morley JE, Thomas D, Nourhashemi F, et al. Wandering behavior and Alzheimer disease. The REAL.FR prospective study. Alzheimer Dis Assoc Disord. 2007;21(1):31-8.

60. McKhann GM, Albert MS, Grossman M, Miller B, Dickson D, Trojanowski JQ; Work Group on Frontotemporal Dementia and Pick's Disease. Clinical and pathological diagnosis of frontotemporal dementia: report of the Work Group on Frontotemporal Dementia and Pick's Disease. Archives of neurology 58, 1803-1809 (2001).

61. Jul P, Volbracht C, de Jong IE, Helboe L, Elvang AB, Pedersen JT. Hyperactivity with Agitative-Like Behavior in a Mouse Tauopathy Model. Journal of Alzheimer's Disease: JAD. 2016;49(3):783-95.

62. Webster SJ, Bachstetter AD, Nelson PT, Schmitt FA, Van Eldik LJ. Using mice to model Alzheimer's dementia: an overview of the clinical disease and the preclinical behavioral changes in 10 mouse models. Front Genet. 2014;5:88.

63. Lewis J, McGowan E, Rockwood J, Melrose H, Nacharaju P, Van Slegtenhorst M, et al. Neurofibrillary tangles, amyotrophy and progressive motor disturbance in mice expressing mutant (P301L) tau protein. Nature Genetics. 2000;25(4):402-5.

64. Rammes G, Steckler T, Kresse A, Schutz G, Zieglgansberger W, Lutz B. Synaptic plasticity in the basolateral amygdala in transgenic mice expressing dominant-negative cAMP response elementbinding protein (CREB) in forebrain. The European Journal of Neuroscience. 2000;12(7):2534-46.

65. Michalon A, Koshibu K, Baumgartel K, Spirig DH, Mansuy IM. Inducible and neuron-specific gene expression in the adult mouse brain with the rtTA2S-M2 system. Genesis. 2005;43(4):205-12.

66. Cook C, Dunmore JH, Murray ME, Scheffel K, Shukoor N, Tong J, Castanedes-Casey M, Phillips V, Rousseau L, Penuliar MS, Kurti A, Dickson DW, Petrucelli L, Fryer JD. Severe amygdala dysfunction in a MAPT transgenic mouse model of frontotemporal dementia. Neurobiology of aging 35, 1769-1777 (2014).

67. Treit D, Fundytus M. Thigmotaxis as a test for anxiolytic activity in rats. Pharmacology, Biochemistry, and Behavior. 1988;31(4):95962.

68. Simon P, Dupuis R, Costentin J. Thigmotaxis as an index of anxiety in mice. Influence of dopaminergic transmissions. Behavioural Brain Research. 1994;61(1):59-64.
69. Yue, M., Hanna, A., Wilson, J., Roder, H. \& Janus, C. Sex difference in pathology and memory decline in rTg4510 mouse model of tauopathy. Neurobiology of aging 32, 590-603 (2011).

70. Martin-Bastida A, Ward RJ, Newbould R, Piccini P, Sharp D, Kabba C, et al. Brain iron chelation by deferiprone in a phase 2 randomised double-blinded placebo controlled clinical trial in Parkinson's disease. Scientific Reports. 2017;7(1):1398.

71. Foidl BM, Humpel C. Differential Hyperphosphorylation of TauS199, -T231 and -S396 in Organotypic Brain Slices of Alzheimer Mice. A Model to Study Early Tau Hyperphosphorylation Using Okadaic Acid. Frontiers in Aging Neuroscience. 2018;10:113.

72. Augustinack JC, Schneider A, Mandelkow EM, Hyman BT. Specific tau phosphorylation sites correlate with severity of neuronal cytopathology in Alzheimer's disease. Acta Neuropathologica. 2002;103(1):26-35.

73. Asuni AA, Boutajangout A, Quartermain D, Sigurdsson EM. Immunotherapy targeting pathological tau conformers in a tangle mouse model reduces brain pathology with associated functional improvements. The Journal of Neuroscience: the Official Journal of the Society for Neuroscience. 2007;27(34):9115-29.

74. Cowan CM, Mudher A. Are tau aggregates toxic or protective in tauopathies? Front Neurol. 2013;4:114.

75. Bolos M, Pallas-Bazarra N, Terreros-Roncal J, Perea JR, JuradoArjona J, Avila J, et al. Soluble Tau has devastating effects on the structural plasticity of hippocampal granule neurons. Transl Psychiatry. 2017;7(12):1267.

76. Kontoghiorghes GJ, Goddard JG, Bartlett AN, Sheppard L. Pharmacokinetic studies in humans with the oral iron chelator 1, 2-dimethyl-3-hydroxypyrid-4-one. Clinical Pharmacology and Therapeutics. 1990;48(3):255-61.

77. Hanger DP, Anderton BH, Noble W. Tau phosphorylation: the therapeutic challenge for neurodegenerative disease. Trends in Molecular Medicine. 2009;15(3):112-9.

78. Noble W, Olm V, Takata K, Casey E, Mary O, Meyerson J, et al. $\mathrm{Cdk} 5$ is a key factor in tau aggregation and tangle formation in vivo. Neuron. 2003;38(4):555-65.

79. Lovell MA, Xiong S, Xie C, Davies P, Markesbery WR. Induction of hyperphosphorylated tau in primary rat cortical neuron cultures mediated by oxidative stress and glycogen synthase kinase- 3 . Journal of Alzheimer's Disease: JAD. 2004;6(6):659-71; discussion 73-81.

80. Munoz P, Zavala G, Castillo K, Aguirre P, Hidalgo C, Nunez MT. Effect of iron on the activation of the MAPK/ERK pathway in PC12 neuroblastoma cells. Biological Research. 2006;39(1):18990 .

81. Sontag E, Luangpirom A, Hladik C, Mudrak I, Ogris E, Speciale S, et al. Altered expression levels of the protein phosphatase $2 \mathrm{~A}$ $\mathrm{ABalphaC}$ enzyme are associated with Alzheimer disease pathology. Journal of Neuropathology and Experimental Neurology. 2004;63(4):287-301.

82. Sontag E, Hladik C, Montgomery L, Luangpirom A, Mudrak I, Ogris E, et al. Downregulation of protein phosphatase 2A carboxyl methylation and methyltransferase may contribute to Alzheimer disease pathogenesis. Journal of Neuropathology and Experimental Neurology. 2004;63(10):1080-91.

83. Louis JV, Martens E, Borghgraef P, Lambrecht C, Sents W, Longin $\mathrm{S}$, et al. Mice lacking phosphatase PP2A subunit PR61/B'delta (Ppp2r5d) develop spatially restricted tauopathy by deregulation of CDK5 and GSK3beta. Proceedings of the National Academy of Sciences of the United States of America. 2011;108(17):695762.

Publisher's Note Springer Nature remains neutral with regard to jurisdictional claims in published maps and institutional affiliations. 